\title{
FAKTOR YANG MEMPENGARUHI KELUHAN MUSCULOSKELETAL DISORDER PADA PEKERJA PENGGILINGAN PADI KABUPATEN PENAJAM PASER UTARA
}

\author{
Agus Wiranto', Iwan M. Ramdan², Dina Lusiana ${ }^{3}$ \\ 1,2,3)Departemen Keselamatan dan Kesehatan Kerja, Fakultas Kesehatan Masyarakat \\ Universitas Mulawarman, Samarinda, Kalimantan Timur, Indonesia \\ Email: wirantoagus@gmail.com
}

\begin{abstract}
Rice milling is an informal sector which still lacks attention in terms of occupational health and safety aspects. Health problems experienced by one of them are complaints of musculoskeletal disorders (MSDs) which have an impact on decreasing work productivity. This study aims to determine the factors that influence complaints of musculoskeletal disorders (MSDs) in rice milling workers in Sepaku Sub-district, Penajam Paser Utara Regency. This research is a quantitative study with cross sectional research design. Sampling using purposive sampling method that amounted to 35 people. Data analysis used the rank-spearman test with a significance level of 0.05 (5\%). The results showed that there was a significant relationship between work posture $(p=0,000)$ and the risk of manual handling material $(M M H)(p=0.005)$, with complaints of musculoskeletal disorders (MSDs). Whereas in the physical workload, there was no association with complaints of musculoskeletal disorders (MSDs) $(p=0.095)$. It is suggested for workers to do material manual handling $(\mathrm{MMH})$ with the correct procedure, reduce awkward work postures during work and stretch the muscles before working and adequate rest so as to reduce fatigue and perceived muscle tension.
\end{abstract}

Keywords : Material Manual Handling (MMH), Musculoskeletal disorders (MSDs), Work Posture, Physical Workload.

\begin{abstract}
ABSTRAK
Penggilingan padi merupakan sektor informal yang masih minim perhatian dari segi aspek kesehatan dan keselamatan kerja. Masalah kesehatan yang dialami salah satunya keluhan musculoskeletal disorders (MSDs) yang berdampak pada penurunan produktivitas kerja. Penelitian ini bertujuan untuk mengetahui faktor yang mempengaruhi keluhan muskuloskeletal disorders (MSDs) pada pekerja penggilingan padi di Kecamatan Sepaku, Kabupaten Penajam Paser Utara. Penelitian ini merupakan penelitian kuantitatif dengan desain penelitian cross sectional. Pengambilan sampel menggunakan metode purposive sampling yang berjumlah 35 orang. Analisis data menggunakan uji rankspearman dengan level signifikansi $0,05(5 \%)$. Hasil penelitian menunjukan bahwa ada hubungan yang signifikan antara postur kerja $(p=0,000)$ dan risiko material manual handling $(\mathrm{MMH})(\mathrm{p}=0,005)$ dengan keluhan musculoskeletal disorders (MSDs). Sedangkan pada beban kerja fisik, tidak terdapat hubungan dengan keluhan musculoskeletal disorders (MSDs) $(p=0,095)$. Disarankan pada pekerja melakukan material manual handling $(\mathrm{MMH})$ dengan prosedur yang benar, mengurangi postur kerja janggal selama bekerja dan melakukan peregangan otot sebelum bekerja serta istirahat yang cukup agar dapat mengurangi kelelahan dan ketegangan otot yang dirasakan.
\end{abstract}

Kata Kunci: Material Manual Handling (MMH), Musculoskeletal Disorders (MSDs) Postur Kerja, Beban Kerja Fisik 
PENDAHULUAN

Dalam meningkatkan taraf
hidup masyarakat dan
kesejahteraan, pemerintah ber-
upaya dengan meningkatkan
pembangunan nasional yang
salah satunya adalah
pembangunan sektor industri.
Perkembangan industri di
Indonesia mengalami
peningkatan baik dalam industri
formal dan informal. Sektor
informal merupakan sektor yang
masih minim mendapat perhatian
dari aspek kesehatan dan
keselamatan kerja, yang berakibat banyaknya keluhan mengenai masalah kesehatan yang diderita tenaga kerja. Menurut Depkes 2016, masalah kesehatan yang sering terjadi seperti gangguan otot rangka atau musculoskeletal disorders (MSDs), gangguan mata dan gangguan kesehatan kulit.

Sektor informal khususnya dibidang pertanian dianggap sebagai sektor berbahaya bagi pekerja dari segala usia. Pekerja pertanian memiliki tingkat kecelakaan dan penyakit akibat kerja yang tinggi, karena mereka dihadapkan pada berbagai bahaya, diantaranya termasuk bekerja dengan berbagai peralatan dan mesin, kebutuhan untuk mengangkat beban berat dan melakukan pekerjaan berulang serta pekerjaan yang membutuhkan posisi canggung yang dapat mengakibatkan MSDs. (ILO, 2018).

Menurut National Institute of Occupational Safety and Health (NIOSH) tahun 2018, MSDs merupakan cedera jaringan lunak yang disebabkan oleh paparan yang tiba-tiba atau berkelanjutan terhadap gerakan berulang, gaya, getaran, dan posisi yang canggung. Gangguan ini dapat mempengaruhi otot, ligamen, saraf, tendon, dan persendian,

Berdasarkan data Bereau of Labor Statistic U.S Department of Labor (BLS) pada tahun 2015 kasus musculoskeletal disorders (MSDs) yang di sebabkan pekerjaan yang terlalu dipaksakan dalam proses mengangkat berjumlah 356.910 kasus atau $31 \%$ dari semua kasus kecelakaan di tempat kerja dan penyakit akibat kerja. Menurut data Labour Force Survei (LFS) Great Britain tahun 2017 kasus musculoskeletal disorders menempati urutan kedua dengan rata - rata prevalensi 469.000 kasus atau $34,54 \%$ selama 3 tahun terakhir dari semua kasus penyakit akibat kerja yang ada.

Penelitian yang dilakukan oleh Abdilah (2013), pada kuli angkut buah di Pasar Johar Semarang. bertujuan menganalisis postur kerja dengan menggunakan metode RULA. Dengan hasil postur kerja $60 \%$ 
responden berada pada action level 4 yang berisiko tinggi pada sistem musculoskletal dan $80 \%$ dari responden merasakan sakit pada punggung dan pinggang.

Penelitian yang di lakukan oleh Bintang dan Dewi (2017), mengenai analisa postur kerja terhadap aktivitas pengangkutan gula pada gudang penyimpanan Pabrik Gula Tjoekir Jombang Jawa Timur. Didapatkan perhitungan metode OWAS dengan skor level resiko 3 , dan skor level risiko metode RULA sebesar 4 yang artinya dapat menyebabkan cedera musculoskeletal sehingga diperlukan adanya perbaikan segera untuk mengurangi resiko terjadinya cedera.

Dibidang pertanian proses penggilingan padi merupakan sektor informal yang mempunyai faktor bahaya ergonomi. Hal ini dikarenakan pada proses penggilingan walaupun menggunakan mesin tetapi masih membutuhkan tenaga kerja untuk kegiatan pengoprasian mesin, kegiatan angkat - angkut (manual handling), dan banyak menerapkan sikap kerja yang tidak alamiah dari proses kerjanya.

Dari data dinas pertanian kabupaten Penajam Paser Utara, Kecamatan Sepaku merupakan kecamatan yang memiliki penggilingan padi kedua terbanyak yang tersebar di 14 desa. Dari hasil wawancara dan studi pendahuluan yang dilakukan pada salah satu penggilingan padi menunjukkan seluruh tenaga kerja yang berjumlah 3 orang mengeluhkan adanya sakit pada beberapa anggota bagian tubuh seperti leher, bahu, punggung, dan pinggang yang merupakan tandatanda dari keluhan musculoskeletal disorders (MSDs). Berdasarkan hasil observasi, postur kerja yang mereka lakukan tergolong postur kerja yang tidak alamiah karena banyak sikap membungkuk, memutar punggung, mengangkat beban berat dan dilakukan berulang kali yang berpotensi menimbulkan gangguan muskulo-skeletal yang berdampak pada produktivitas pekerja penggilingan padi tersebut.

Berdasarkan deskripsi diatas, peneliti tertarik melakukan penelitian untuk mengetahui faktor-faktor yang mempengaruhi keluhan musculoskeletal disorders pada pekerja di penggilingan padi di Kecamatan Sepaku Kabupaten Penajam Paser Utara.

\section{METODE PENELITIAN}

Jenis penelitian yang digunakan adalah kuantitatif dengan pendekatan cross sectional. Penelitian ini dilakukan 
di Penggilingan Padi yang terletak di Kecamatan Sepaku, Kabupaten Penajam Paser Utara pada bulan September November tahun 2018. Jumlah sampel pada penelitian ini adalah sebanyak 35 tenaga kerja dengan teknik sampling yang digunakan adalah Purposive Sampling. Variabel Independen dalam penelitian ini adalah postur kerja, resiko material manual handling dan beban kerja fisik. Sedangkan untuk variabel dependen yaitu keluhan musculoskletal disorders (MSDs).

Cara pengumpulan data yang digunakan terdiri dari metode kuesioner, metode observasi, dan pengukuran langsung. Instrumen penelitian yang digunakan adalah lembar identitas umum sekaligus perhitungan beban kerja fisik atau persen cardiovascular load (\%CVL), kuesioner nordic body map, lembar observasi over working analysis system (OWAS), dan lembar observasi material manual handling ( $\mathrm{MMH})$. Teknik analisis data yang digunakan terdiri dari analisis univariat dan analisis bivariat menggunakan uji Korelasi Rank Spearman dengan nilai signifikansi $95 \%$ atau $\alpha=0.05$.

\section{HASIL DAN PEMBAHASAN \\ Hasil}

Penelitian ini dilakukan pada 35 pekerja yang memenuhi kriteria dari 26 penggilingan padi yang tersebar di 10 di kecamatan Sepaku Kabupaten Penajam Paser Utara. Distribusi karaketeristik responden dapat dilihat pada tabel berikut:

Tabel 1. Distribusi Karakerisitik Responden

\begin{tabular}{clcc}
\hline No & Kategori & $\mathbf{f}$ & $\mathbf{\%}$ \\
\hline 1. & Umur & & \\
& a. $<35$ Tahun & 10 & 28,6 \\
& b. $\geq 35$ Tahun & 25 & 71,4 \\
2. & Masa Kerja & & \\
& a. $<7$ Tahun & 15 & 42,9 \\
b. $\geq 7$ Tahun & 20 & 57,1 \\
3. & IMT & 1 & 2,9 \\
& a. Kurus & 25 & 71,4 \\
b. Normal & 2 & 5,7 \\
& c. Gemuk & 7 & 20,0 \\
d. Obesitas & & \\
4. Pendidikan & 9 & 25,7 \\
& a. SD/Sederajat & 10 & 28,6 \\
b. SMP/Sederajat & 10 & \\
c. SMA/Sederajat & 16 & 45,7 \\
\hline
\end{tabular}

Berdasarkan tabel 1 dapat diketahui bahwa jumlah terbesar pekerja penggilingan padi pada kategori umur $\geq 35$ tahun dengan frekuensi $(71,4 \%)$, masa kerja $\geq 7$ tahun dengan frekuensi $(57,1 \%)$, IMT normal dengan frekuensi (71,4\%) dan Pendidikan SMA/ Sederajat dengan frekuensi $(45,7 \%)$.

Berdasarkan hasil pengumpulan data yang 
dilakukan pada pekerja keluhan musculoskeletal dispenggilingan padi di Kecamatan orders (MSDs) beban kerja fisik, Sepaku, Kabupaten Penajam postur kerja, dan resiko material Paser Utara didapatkan manual handling $(\mathrm{MMH})$ sebagai gambaran data dari variabel berikut:

Tabel 2. Distribusi Responden Menurut Tingkat Keluhan MSDs

\begin{tabular}{llcc}
\hline No & Tingkat Keluhan & $\mathbf{f}$ & \% \\
\hline 1 & Tidak ada keluhan & 0 & 0 \\
2 & Ringan & 6 & 17.1 \\
3 & Sedang & 22 & 62.9 \\
4 & Berat & 7 & 20.0 \\
\hline
\end{tabular}

Berdasarkan tabel 2, dapat diketahui bahwa jumlah terbesar tingkat keluhan MSDs berada pada tingkat keluhan sedang dengan frekuensi 22 responden $(62,9 \%)$.

Tabel 3. Hasil skoring pada tingkat keluhan yang dirasakan perbagian tubuh

\begin{tabular}{|c|c|c|c|c|c|c|}
\hline \multirow{3}{*}{ Bagian Tubuh } & \multicolumn{6}{|c|}{ Skor } \\
\hline & \multicolumn{2}{|c|}{1} & \multicolumn{2}{|c|}{2} & \multicolumn{2}{|c|}{3} \\
\hline & $\mathbf{f}$ & $\%$ & $\mathbf{f}$ & $\%$ & $\mathbf{f}$ & $\%$ \\
\hline Leher Atas & 29 & 82,9 & 4 & 11,4 & 0 & 0 \\
\hline Tengkuk & 22 & 62,9 & 12 & 34,3 & 0 & 0 \\
\hline Bahu Kiri & 17 & 48,6 & 15 & 42,9 & 3 & 8,6 \\
\hline Bahu Kanan & 16 & 45,7 & 16 & 45,7 & 3 & 8,6 \\
\hline Lengan Atas Kiri & 17 & 48,6 & 17 & 48,6 & 0 & 0 \\
\hline Lengan Atas Kanan & 17 & 48,6 & 17 & 48,6 & 0 & 0 \\
\hline Punggung & 7 & 20 & 24 & 68,6 & 4 & 11,4 \\
\hline Pinggang & 1 & 2,9 & 25 & 71,4 & 9 & 25,7 \\
\hline Pinggul & 1 & 2,9 & 26 & 74,3 & 8 & 22,9 \\
\hline Pantat & 2 & 5,7 & 0 & 0 & 0 & 0 \\
\hline Siku Kiri & 19 & 54,3 & 1 & 2.9 & 0 & 0 \\
\hline Siku Kanan & 19 & 54,3 & 1 & 2.9 & 0 & 0 \\
\hline Lengan Bawah Kiri & 23 & 65,7 & 9 & 25,7 & 0 & 0 \\
\hline Lengan Bawah Kanan & 24 & 68,6 & 8 & 22,9 & 0 & 0 \\
\hline Pergelangan Tangan Kiri & 7 & 20 & 1 & 2,9 & 0 & 0 \\
\hline Pergelangan Tangan Kanan & 8 & 22,9 & 1 & 2,9 & 0 & 0 \\
\hline Tangan Kiri & 13 & 37,1 & 1 & 2,9 & 0 & 0 \\
\hline Tangan Kanan & 14 & 40 & 0 & 0 & 0 & 0 \\
\hline Paha Kiri & 27 & 77,1 & 7 & 20 & 0 & 0 \\
\hline Paha Kanan & 26 & 74,3 & 8 & 22,9 & 0 & 0 \\
\hline Lutut Kiri & 27 & 77.1 & 5 & 14,3 & 0 & 0 \\
\hline Lutut Kanan & 25 & 71,4 & 5 & 14,3 & 0 & 0 \\
\hline Betis Kiri & 21 & 60 & 14 & 40 & 0 & 0 \\
\hline Betis Kanan & 21 & 60 & 14 & 40 & 0 & 0 \\
\hline Pergelangan Kaki Kiri & 12 & 34,3 & 0 & 0 & 0 & 0 \\
\hline Pergelangan Kaki Kanan & 10 & 28,6 & 0 & 0 & 0 & 0 \\
\hline Kaki Kiri & 11 & 31,4 & 0 & 0 & 0 & 0 \\
\hline Kaki Kanan & 10 & 28,6 & 0 & 0 & 0 & 0 \\
\hline
\end{tabular}


Berdasarkan tabel 3 dapat diketahui bahwa bagian tubuh dengan keluhan terbanyak pada nilai keluhan skor 2 dan 3 ada pada bagian punggung sebanyak $68,6 \%$ dan $11,4 \%$, pinggang $71,4 \%$ dan $25,7 \%$, pinggul sebanyak $74,3 \%$ dan $22,9 \%$.

Tabel 4. Distribusi Responden Menurut Beban Kerja Fisik

\begin{tabular}{clcc}
\hline No & Beban Kerja Fisik & $\mathrm{f}$ & $\%$ \\
\hline 1 & Ringan & 5 & 14,3 \\
2 & Sedang & 30 & 85,7 \\
3 & Agak berat & 0 & 0 \\
4 & Berat & 0 & 0 \\
5 & Sangat Berat & 0 & 0 \\
\hline
\end{tabular}

Berdasarkan tabel 4, dapat diketahui jumlah terbesar tingkat beban kerja fisik pada kategori sedang dengan frekuensi 30 responden $(85,7 \%)$.

Tabel 5. Distribusi Responden Menurut resiko postur kerja (OWAS)

\begin{tabular}{clcc}
\hline No & Resiko Postur Kerja & $\mathrm{f}$ & $\%$ \\
\hline 1 & Rendah & 0 & 0 \\
2 & Sedang & 13 & 37,1 \\
3 & Tinggi & 22 & 62,9 \\
4 & Sangat Tinggi & 0 & 0 \\
\hline
\end{tabular}

Berdasarkan tabel 5 dapat diketahui jumlah terbesar resiko postur kerja pada kategori tinggi dengan frekuensi 22 responden $(62,9 \%)$.
Tabel 6.Distribusi Responden Menurut resiko MMH

\begin{tabular}{clcc}
\hline No & Resiko MMH & $\mathbf{f}$ & $\%$ \\
\hline 1 & Rendah & 0 & 0 \\
2 & Sedang & 23 & 65.7 \\
3 & Tinggi & 12 & 34.3 \\
4 & Sangat tinggi & 0 & 0 \\
\hline
\end{tabular}

Berdasarkan tabel 6 dapat diketahui jumlah terbesar resiko $\mathrm{MMH}$ pada kategori sedang dengan frekuensi 23 responden (65,7\%).

Ada tidaknya korelasi dinyatakan melalui nilai signifikan $p$-value. Jika nilai $p$-value $<0,05$ sehingga menolak $\mathrm{Ho}$ dan menerima $\mathrm{Ha}$ yang berarti terdapat hubungan diantara kedua variabel.

Berdasarkan hasil analisa dengan menggunakan uji spearman, didapatkan hasil nilai signifikan $p$-value dapat dilihat pada tabel berikut:

Tabel 7. Hubungan faktor faktor dengan keluhan MSDs

\begin{tabular}{llcc}
\hline \multicolumn{1}{c}{$\begin{array}{c}\text { Variabel } \\
\text { Faktor yang }\end{array}$} & \multicolumn{2}{l}{ Keluhan MSDs } & \\
Mempengaruhi & p-value & $\alpha$ & $r$ \\
\hline Postur Kerja & 0,000 & & 0,616 \\
Resiko MMH & 0,005 & 0,05 & 0,461 \\
Beban Kerja & 0,095 & & 0,287 \\
Fisik & & &
\end{tabular}

Berdasarkan tabel 7 terdapat 2 variabel yang mempunyai hubungan yaitu postur kerja $p$-value $(0,000) r(0,616)$ menunjukan ada hubungan yang kuat dan resiko $\mathrm{MMH} p$-value $(0,005)$ r $(0,461)$ menunjukkan hubungan cukup kuat (sedang) dengan keluhan MSDs. 
Pembahasan

\section{Hubungan antara Postur Kerja dengan Keluhan Musculo- skeletal disorders (MSDs)}

Berdasarkan hasil analisis menggunakan uji rank-spearman diperoleh nilai $p$-value $(0,00)<\alpha$ $(0,05)$. Hal ini berarti dapat diketahui ada hubungan antara postur kerja dengan keluhan musculoskeletal disorders (MSDs) berdasarkan correlation coefficient $(R)$ sebesar 0,616 hal tersebut menunjukan ada hubungan yang kuat antara postur kerja dengan keluhan musculoskeletal disorders (MSDs) pada pekerja penggilingan padi di Kecamatan Sepaku Kabupaten Penajam Paser Utara.

Dalam pekerjaan menggiling padi banyak di temukan postur janggal, Postur janggal adalah postur dimana posisi tubuh menyimpang secara signifikan dari posisi netral seperti membungkuk saat mengangkat, memutar punggung dan tubuh, pergerakan tangan terangkat. Menurut Reese (2009) postur janggal signifikan berkontribusi terjadinya MSDs karena meningkatkan beban kerja otot. Semakin jauh posisi bagian tubuh dari pusat gravitasi tubuh (posisi netral), maka semakin tinggi pula resiko terjadinya keluhan sistem musculoskeletal.
Berdasarkan analisis postur kerja menggunakan metode OWAS didapati bahwa tingkat risiko postur sedang sebanyak $37,1 \%$, sedangkan yang bekerja dengan tingkat risiko postur tinggi sebanyak $(62,9 \%)$ untuk pekerja dengan resiko postur kerja tinggi berdasarkan penilaian OWAS ada pada proses mengambil padi, menuang padi ke corong mesin pecah kulit, mengangkat bak beras dan menuang beras ke karung dengan hasil keluhan musculoskeletal disorders yang banyak terjadi keluhan pada bagian pinggang, punggung,dan pinggul.

Tarwaka (2015) menjelaskan postur kerja yang dipaksakan seperti membungkuk, melakukan pekerjaan di tempat yang tidak rata dan melakukan pengangkatan berulang dapat menyebabkan adanya pelemahan pada dinding disc diantara masing-masing tulang belakang. Pelemahan dinding disc tersebut mengakibatkan terjadinya penonjolan. Tonjolan disc akan memberikan tekanan pada syaraf bagian dalam dan sekitar disc yang dirasakan sebagai kenyerian.

Hal ini tidak hanya memberikan tekanan tambahan pada disc dan syaraf saja, tetapi juga akan membuat tulang belakang bagian atas dan bawah jadi tidak stabil. Kondisi ini juga akan menyebabkan stres pada 
otot dan ligamen pada tulang belakang.Untuk rasa kenyerian yang berkaitan dengan masalah disc tersebut dapat pula dihubungkan dengan gangguan atau ketegangan otot dan ligamen. Gangguan berupa kenyerian tersebut terjadi pada saat tulang belakang membungkuk terlalu jauh, membungkuk secara berulang atau pada saat membungkuk dengan membawa beban.

Hal ini dapat terjadi karena posisi membungkuk saat mengangkat beban, tulang belakang terutama bagian pinggang sebagai titik fulcrum (tumpu) mengalami tekanan kompresif. Tekanan kompresif yang dialami adalah 20 kali dari berat beban yang diangkat, tidak hanya jarak beban dari tubuh saja yang berpengaruh menyumbangkan tekanan kompresif, tetapi juga berat tubuh yang membungkuk ke depan. Dengan demikian walaupun seseorang tidak mengangkat beban sekalipun, tekanan kompresif tetap akan dihasilkan hanya untuk mempertahankan tubuh dalam posisi membungkuk tersebut (Tarwaka, 2015).

Penelitian ini sejalan dengan peneilitian Ulfah (2014) mengenai hubungan sikap kerja dengan keluhan musculoskeletal disorders (MSDs) pada pekerja Laundry di Kecamatan
Purwokerto yang menemukan ada hubungan sikap kerja dengan keluhan MSDs (nilai $p=$ $0,041<\alpha=0,05)$ hal ini dikarenakan pekerja melakukan pencucian dengan posisi punggung membungkuk dan cara mengangkat dengan posisi beban tidak didekatkan dengan tubuh. Posisi tersebut kemungkinan menjadi salah satu penyebab adanya keluhan MSDs.

Hal ini diperkuat oleh penelitian Ramdan (2012) mengenai determinan keluhan musculoskeletal disorder pada tenaga kerja wanita yang menemukan ada hubungan antara sikap kerja dengan keluhan MSDs (nilai $p=0,001<$ $\alpha=0,05)$ hal ini dikarenakan sikap berdiri merupakan sikap siaga baik fisik dan mental, sehingga aktivitas kerja yang dilakukan lebih cepat, kuat, dan teliti. Pada dasarnya, berdiri lebih melelahkan daripada duduk, energi yang dikeluarkan untuk berdiri lebih banyak $10-15 \%$ dibandingkan duduk.

Namun penelitian ini berbeda dengan penelitian Icsal (2016) mengenai faktor yang berhubungan dengan keluhan musculoskeletal disorders (MSDs) pada penjahit wilayah pasar panjang kota kendari yang menemukan tidak ada hubungan antara postur kerja dengan keluhan MSDs (nilai $p=0,108>$ 
$\alpha=0,05)$ hal ini dipengaruhi sebab posisi tubuh penjahit tidak terlalu banyak membungkuk, tidak ada gerakan memuntir badan, dan lebih banyak bekerja dengan posisi duduk tidak membutuhkan energi yang banyak dibandingkan dengan sikap kerja berdiri.

\begin{tabular}{|c|c|c|}
\hline $\begin{array}{l}\text { Hubungan } \\
\text { Material } \\
\text { (MMH) }\end{array}$ & $\begin{array}{l}\text { antara } \\
\text { Manual } \\
\text { dengan }\end{array}$ & $\begin{array}{r}\text { Resiko } \\
\text { Handling } \\
\text { Keluhan }\end{array}$ \\
\hline $\begin{array}{l}\text { Musculosk } \\
\text { MSDs) }\end{array}$ & keletal & \\
\hline
\end{tabular}

Berdasarkan hasil analisis menggunakan uji rank-spearman diperoleh nilai $p$-value $(0,005)<\alpha$ $(0,05)$. Hal ini berarti dapat diketahui ada hubungan antara resiko material manual handling (MMH) dengan keluhan musculoskeletal disorders (MSDs) berdasarkan correlation coefficient $(R)$ sebesar 0,461 hal tersebut menunjukan ada hubungan cukup kuat antara resiko material manual handling (MMH) dengan keluhan musculoskeletal disorders (MSDs).

Dari hasil penelitian didapat resiko $\mathrm{MMH}$ tingkat sedang sebanyak $65,7 \%$ dan resiko $\mathrm{MMH}$ tingkat tinggi sebanyak $34,3 \%$. Dalam penilaian resiko $\mathrm{MMH}$ pengkategorian berdasarkan skor hasil hitung dari 4 parameter yaitu waktu atau frekuensi (total 1 hari kerja), beban angkut, sikap membawa beban, dan kondisi lingkungan. Berdasarkan correlation coefficient yang bernilai positif artinya semakin tinggi nilai 4 parameter mempengaruhi tingginya resiko $\mathrm{MMH}$ tersebut semakin tinggi pula keluhan MSDs yang dirasakan.

Tarwaka (2015) menyebutkan bahwa pekerjaan manual handling akan dapat menyebabkan stress pada kondisi fisik pekerja (seperti: pengerahan tenaga, sikap tubuh yang dipaksakan dan gerakan berulang) yang dapat mengakibatkan terjadinya cedera, energi terbuang secara percuma dan waktu kerja tidak efisien. Aktivitas manual handling yang di lakukan oleh pekerja di penggilingan di Kecamatan Sepaku Kabupaten Penajam Paser Utara banyak ditemukan postur janggal membungkuk dan gerakan berulang dengan banyak keluhan terjadi pada daerah pinggang, punggung dan pinggul.

Penelitian ini sejalan dengan penelitian yang dilakukan Beverly (2015) yang menemukan adanya hubungan antara aktivitas manual handling dengan keluhan musculoskeletal pada pekerja bangunan di PT. Fatcons Manado (nilai $p=0,049<\alpha=$ $0,05)$ yang dalam aktivitas manual handlingnya banyak melakukan gerakan repetitive 
dengan postur janggal dan beban yang cukup berat.

Hal ini di perkuat oleh penelitian yang dilakukan Saputro (2016) yang menemukan adanya hubungan antara risiko manual handling dengan keluhan low back pain pada pekerja bagian penuangan cor logam di PT. Aneka Adhi Logam Karya Ceper Klaten (nilai $p=0,004<\alpha=$ $0,05)$. Hal ini di pengaruhi oleh posisi punggung yang membungkuk saat melakukan manual handling karena apabila aktivitas tersebut sering dilakukan dengan postur kerja yang buruk seperti membungkuk maka akan menimbulkan keluhan MSDs yang terjadi pada pinggang (low back pain).

\section{Hubungan antara Beban Kerja Fisik dengan Keluhan Musculoskeletal disorders (MSDs).}

Berdasarkan hasil analisis menggunakan uji rank-spearman diperoleh nilai $p$-value $(0,09)>\alpha$ $(0,05)$. Hal ini berarti dapat diketahui tidak ada hubungan antara beban kerja dengan keluhan musculoskeletal disorders (MSDs) pada pekerja penggilingan padi di Kecamatan Sepaku Kabupaten Penajam Paser Utara.

Pekerjaan menggiling padi merupakan pekerjaan dengan postur dinamis. Postur Dinamis menurut Keyserling (2006) yaitu postur dimana sebagian besar otot melakukan kontraksi dan rileks berkali - kali dalam bekerja postur dinamis di batasi oleh kapasitas dari sistem pernapasan dan peredaran darah yang berhubungan dengan suplai oksigen dan glukosa ke otot yang bekerja dan menghilangkan produk sisa metabolisme otot. Kelelahan otot dapat terjadi apabila tuntutan metabolisme dari otot yang bekerja melebihi kapasitas yang ada.

Beban kerja fisik dikategorikan berdasarkan persen cardiovaskuler load dengan pengukuran denyut nadi. Beban kerja fisik seseorang dapat berhubungan dengan keluhan MSDs apabila beban kerja fisik tersebut menyebabkan kontraksi otot yang berlebihan akibat pembebanan berlebihan dengan durasi pembebanan panjang yang menyebabkan kelelahan otot karena kurangnya suplai oksigen yang mengakibatkan penumpukan sisa metabolisme (asam laktat) dan menimbukan rasa ketidaknyamanan, pegal atau nyeri. Penumpukan asam laktat tidak terjadi apabila tersedianya waktu pemulihan untuk otot mendapatkan suplai oksigen yang cukup untuk menghilangkan asam laktat sebelum terjadi penumpukan (Tarwaka, 2015). 
Dari hasil observasi, responden mempunyai waktu pemulihan atau rileks disela sela menunggu bak - bak berisi beras penuh dari mesin pecah kulit dan menunggu padi habis dari penampung mesin pecah kulit sebelum melakukan pengangkatan kembali. hal ini didukung dari hasil penelitian didapati bahwa kategori beban kerja beban kerja ringan sebanyak $14,3 \%$, sedangkan yang bekerja dengan tingkat beban kerja sedang sebanyak $85,7 \%$. Hal ini memungkinkan bahwa keluhan musculoskeletal tidak disebabkan dari kelelahan otot akibat tuntutan terhadap kebutuhan energi hasil metabolisme untuk otot yang bekerja melebihi kapasitas yang ada karena tersedianya waktu rileks dan pemulihan.

Keluhan musculoskeletal yang terjadi dipengaruhi akibat kelelahan dan trauma otot dari faktor resiko yang lain seperti postur kerja, yang tidak ergonomi atau resiko $\mathrm{MMH}$ yang tinggi untuk sistem musculoskeletal. walaupun pekerjaan tersebut didapati beban kerja hanya kategori ringan dan sedang namun apabila dilakukan dengan postur kerja yang tidak ergonomi dan resiko $\mathrm{MMH}$ yang tinggi secara terus menerus akan menyebabkan keluhan musculoskeletal.
Penelitian ini sejalan dengan Sartika (2017) yang menemukan tidak ada hubungan antara beban kerja fisik dengan keluhan low back pain pada penenun traditional sarung Samarinda di Kampung Tenun Samarinda Seberang dengan pvalue 0,343 hal ini dikarenakan mayoritas beban kerja ringan $(73,5 \%)$ namun dikarenakan lebih dikarenakan postur kerja janggal yaitu membungkuk dalam menenun.

Berbeda dengan penelitian Risdianti (2018). yang menemukan hubungan antara Hubungan Antara Beban Kerja dengan Keluhan Low Back Pain (Lbp) Pada Kuli Panggul Perempuan di Pasar Legi Surakarta dengan $p$-value $0,00<$ a 0,05 namun dengan tingkat kekuatan yang sedang dengan correlation coefficient (R) 0,414. Hal ini dikarenakan otot mengalami kelelahan dan menimbulkan keluhan dikarenakan kuli panggul membawa beban yang berat dengan jarak yang cukup jauh dan tidak ada waktu yang cukup untuk waktu pemuliahan recovery.

\section{SIMPULAN}

Keluhan musculoskeletal disorders (MSDs) pada pekerja penggilingan padi di Kecamatan Sepaku di kecamatan Sepaku 
Kabupaten Penajam Paser Utara sebagian besar tergolong keluhan sedang. Proporsi keluhan terbanyak terdapat pada bagian punggung, pinggang, dan pinggul. Keluhan musculoskeletal disorders (MSDs) ini dipengaruhi oleh postur kerja dan resiko material manual handling ( $\mathrm{MMH})$. Disarankan bagi pekerja/pengelola penggilingan sebaiknya menyediakan meja setinggi pinggul (rata-rata tinggi pinggul orang indonesia dewasa laki - laki $=93,6 \mathrm{~cm}$ atau $\pm 1 \mathrm{~m}$ ) untuk memudahkan saat akan mengangkat dan membawa karung padi, menyedian landasan sebagai pijakan setinggi $\pm 20 \mathrm{~cm}$ didekat mesin pemutih agar memudahkan menuang beras, mengurangi postur kerja janggal selama bekerja, dan melakukan material manual handling $(\mathrm{MMH})$ dengan prosedur yang benar. serta melakukan peregangan otot sebelum bekerja dan juga istirahat yang cukup agar dapat mengurangi kelelahan, ketegangan dan keluhan otot.

\section{DAFTAR PUSTAKA}

Abdillah, Fikri. 2013. Analisis Postur Kerja Dengan Metode Rapid Upper Limb Assesment (RULA) Pada Pekerja Kuli ngkut Buah Di Agen Ridho Illahi Pasar Johar Kota Semarang. Semarang : FKM UNDIP.
Dari: $\quad$ http://eprints.undip. ac.id/37888/1/4556.pdf. [ 21 April 2018]

Arofah, Iva Khusnul. dkk. 2015. Faktor-Faktor Yang Berhubungan Dengan Keluhan Muskuloskeletal Disorders (Msds) Pada Buruh Angkut di Pasar Pedurungan dan Pasar Gayamsari Kota Semarang. Semarang: FKM Universitas Muhammadiyah Semarang. Dari:

http://digilib.unimus.ac.id/gdl .php?mod=browse\&op=read \&id=itptunimus-gdl-iva khusnul-7877. [Diunduh: 28 Desember 2018]

BLS. 2016. News Release Nonfatal Occupational Injuries and Illnesses Requiring Days Away From Work, $2015 . \quad$ Dari: https://www.bls.gov/ news.release/archives/osh2 11102016.pdf [20 April 2018]

Beverly, M. 2015. Hubungan Antara Aktivitas Manual Handling Dengan Keluhan Musculoskeletal Pada Pekerja Bangunan Di Pt. Fatcons Manado. Manado : FKM Universitas Sam Ratulangi. Dari: http://medkesfkm.unsrat.ac.i d/wpcontent/uploads/2015/1 1/Mewoh-Beverly.pdf. [15 Desember 2018] 
Departemen Kesehatan RI, 2016. Hidupkan Pos UKK Agar Pekerja Sektor Informal Tersentuh Layanan Kesehatan Kerja. Tersedia dari http://www.depkes.go.id/arti cle/view/16110900002/hidup kan-pos-ukkagarpekeriasektor-informal tersentuhlayanankesehatankerja.html.[12 Juli 2018]

Dewi, Nur Bintang. 2017. Analisa Postur Kerja Menggunakan Metode OWAS dan RULA Aktivitas pengangkutan gula pada gudang penyimpanan PG Tjoekir Jombang Jawa Timur. Malang : Universitas Muhammadiyah Malang. Tersedia dari: http://ejournal.umm.ac.id/ index.php/industri/article/vie wFile/ 4612/pdf.[5 Juni 2018]

Icsal, M.M.A., Sabilu, Y., Pratiwi, A.D. Faktor Yang Berhubungan Dengan Keluhan Musculoskeletal Disorders (Msds) Pada Penjahit Wilayah Pasar Panjang Kota Kendari. Jurnal IImiah Mahasiswa Kesehatan Masyarakat (2016). Vol 1. No. 2. Dari: http://ojs.uho.ac.id/index.ph $\mathrm{p} / \quad$ JIMKESMAS/article/ view/665. [15 Desember 2018]
ILO. 2018. Meningkatkan Keselamatan dan Kesehatan Pekerja Muda. ILO : Indonesia. Dari:https://www.ilo.org/ jakarta/whatwedo/publicatio ns/WCMS627174/lang-en/index.htm. [20 Juni 2018] Keyserling. W. Monroe, 2006. Occupational Ergonomics: Promoting Safety and health Through Work Design. USA : USA: Lippincott Williams dan Wilkins.

Kroemer, Karl H.E, 2009. Fitting The Human : Introduction to Ergonomics Sixth Edition. New York: CRC Press

LFS. 2017. Self-reported workrelated ill health and workplace injuries: Index of LFS tables Tersedia dari: http://www.hse.gov.uk/statist ics/ffs/index.htm. [20 April 2018]

NIOSH. 2018. Muscoskeletal Health Program. Dari: https://www.cdc.gov Iniosh/programs/msd $\quad[10$ Mei 2018]

Ramdan, Iwan Muhammad \& Laksmono, Tiyanpri Bayu. Determinan Keluhan Muskuloskeletal pada Tenaga Kerja Wanita. Jurnal Kesehatan Masyarakat Nasional (2012). Vol. 7, No. 4. Dari: http://journal.fkm.ui.ac. 


\section{idkesmas/article/view/48 [16 \\ Desember 2018] \\ Reese. D.Charles, 2009. \\ Occupational Health and Safety Management : A Practical Aprroach. Second Edition. New York: CRC Press \\ Resdianti, D. 2018. Hubungan Antara Beban Kerja Dengan Keluhan Low Back Pain (Lbp) Pada Kuli Panggul Perempuan Di Pasar Legi Surakarta. Surakarta : Universitas Muhammadiyah Surakarta. Tersedia dari : http://eprints.ums. ac.id/61379/. [15 Desember 2018]}

Saputro, A.W. 2016. Hubungan Risiko Pekerjaan Manual Handling Dengan Keluhan Low Back Pain Pada Pekerja Bagian Penuangan Cor Logam Di Pt. Aneka Adhilogam Karya Ceper Klaten. Surakarta: Universitas Muhammadiyah Surakarta. Dari: http://eprints.ums. ac.id/45527/. [15 Desember 2018]

Sartika, Dewi. 2017. Faktor Faktor Yang Berhubungan dengan Low Back Pain (LBP) Pada Penenun Tradisional Sarung Samarinda Di Kampung Tenun Seberang.
Samarinda:

FKM

Universitas Mulawarman

Suma'mur P.K. 2004. Higiene Perusahaan dan Kesehatan Kerja. Jakarta: PT Toko Gunung Agung.

Stanton. 2005. Handbook Of Human Faktor And Ergonomic Method. America USA: CRC Press.

Tarwaka, 2015. Ergonomi Industri: dasar- dasar pengetahuan ergonomi dan aplikasi di tempat kerja. Solo: Harapan Press.

Ulfah, N., Harwanti, S., \& Nurcahyo, J.P. Sikap Kerja dan Risiko Musculoskeletal Disorders pada Pekerja Laundry. Jurnal Kesehatan Masyarakat Nasional (2014). Vol. 8, No. 7. Dari: http://journal.fkm.ui.ac. id/kesmas/article/view/371. [16 Desember 2018] 